\title{
Hva skriver norske aviser og ukeblader om vond rygg?
}

\author{
Sammendrag \\ Bakgrunn. Informasjon i mediene \\ påvirker holdninger og atferd. Vi ønsket \\ å kartlegge hva norske aviser og \\ ukeblader skriver om ryggsmerter \\ og i hvilken grad det de skriver, er \\ i samsvar med norske tverrfaglige \\ retningslinjer for korsryggssmerter, \\ som ble publisert i 2002.
}

Materiale og metode. Dette er en kvantitativ innholdsanalyse av 495 artikler fra norske aviser og ukeblader publisert i årene 2001-03 og 2005-06.

Resultater. De fleste artiklene omhandlet en person. Risikofaktorer for ryggplager, utredning, behandling og forebygging ble hyppig omtalt. Ingen av artiklene hadde et innhold som brøt direkte med retningslinjenes budskap. Avhengig av medietype understøttet mellom $44 \%$ og $62 \%$ retningslinjenes viktigste budskap om å gjenoppta vanlige aktiviteter, komme tilbake på jobb og sette i gang med øvelser og trening så snart som mulig.

Fortolkning. Norske aviser og ukeblader formidler i stor grad kunnskapsbasert informasjon om vond rygg. Vi oppfatter dem som medspillere for å få frem innholdet i retningslinjene for behandling av korsryggssmerter.

\section{Even Lærum el@formi.no \\ Formidlingsenheten for muskel- og skjelettlidelser (FORMI) Klinikk for kirurgi og nevrofag Oslo universitetssykehus, Ullevål 0407 Oslo}

\section{Sigurd Høye}

Seksjon for allmennmedisin Institutt for helse og samfunn Universitetet i Oslo

Ragnhild Nordland
Vegard Hegstad
Synnøve Tafjord Lærum
Hans Otto Engvold
Formidlingsenheten for muskel-
og skjelettlidelser
Klinikk for kirurgi og nevrofag
Oslo universitetssykehus, Ullevål

Kunnskaper, holdninger og atferd knyttet til helse påvirkes av mange faktorer $(1,2)$, blant annet av innholdet $\mathrm{i}$ aviser og ukeblader. Mye tyder på at mediene har stor og økende betydning (3-7). Medieinformasjon kan ha både positive og negative konsekvenser for folkehelsen. Aviser og ukeblader kan bidra til å spre informasjon og kunnskapsbaserte råd og slik fremme helse og livskvalitet $(1,2)$, men de kan også skape økt helseangst, overdreven risikofokusering, medikalisering og urealistiske forventninger til behandlingstilbud $(2,4,8)$.

Ryggsmerter rammer $60-80 \%$ av befolkningen en eller flere ganger i løpet av livet og koster samfunnet mye, «vond rygg» er den enkeltlidelsen som «plager flest og koster mest» $(9,10)$. Gjennom de siste 20 år er behandlingen i stor grad endret - fra råd om ro og sengeleie og å unngå smerte til gjenopptakelse av vanlige aktiviteter og jobb så fort som mulig $(11,12)$. Det var også hovedbudskapet i kampanjen Aktiv rygg, som ble gjennomført i 2003 til 2005. Der kartla man og prøvde å påvirke befolkningens holdninger til vond rygg $(13,14)$.

I Norge er det publisert tverrfaglige, kunnskapsbaserte retningslinjer for håndtering av korsryggssmerter $(12,13,15)$, første gang i mars 2002. Vi ønsket å undersøke hva norske aviser og ukeblader formidler om vond rygg og i hvilken grad stoffet er i samsvar med eller bryter med retningslinjene. Vi ønsket også å undersøke om formidlingen er endret etter publiseringen av de første retningslinjene.

\section{Materiale og metode}

Formidlingsenheten for muskel- og skjelettlidelser (FORMI) har siden 2001 abonnert på presseklipptjeneste fra medieovervåkningsfirmaet Cision (tidligere Observer Norge) med søkeordene «Nasjonalt ryggnettverk» og «rygg». Byrået har gått gjennom all trykt presse i Norge, inkludert nisjeblader, nyhetsbyråer, tidsskrifter, riksaviser, regionsaviser og lokalaviser. Noe er lest manuelt, resten er automatisk skannet og deretter gjennomsøkt elektronisk. Samtlige artikler som ble identifisert, ble sendt i papirkopi til FORMI.

Vårt materiale består av alle artikler mottatt fra Cision og publisert i periodene 11.7. 2001-1.3. 2003 og 1.3. 2005-1.3. 2006, det vil si perioden fra abonnementsoppstart og til ett år etter retningslinjene ble publisert samt en ettårsperiode tre år etter publiseringen. Artikler der «rygg» ikke var nevnt i overskrift eller ingress, ble ekskludert. Leserbrev og artikler i medisinske fagtidsskrifter ble heller ikke tatt med.

En kodebok for analyse av artiklene ble utviklet av én av forfatterne (SH). Kodeboken ble prøvd ut av to av de andre (SL og EL) på et mindre materiale og deretter utvidet og justert (ramme 1). To av forfatterne ( $\mathrm{RN}$ og VH) ble deretter opplært og veiledet på et annet, mindre materiale. Disse kodet så hver sin halvdel av materialet. Når det oppsto tvil om kodingen, ble artikkelen diskutert med den andre koderen og med en av kodebokforfatterne (SL). Oppslag som besto av flere artikler, ble kodet under ett.

850 artikler ble gjennomlest. 355 artikler $(42 \%)$ ble ekskludert, hovedsakelig fordi «rygg» ikke var nevnt i overskrift eller ingress (265 artikler). Materialet besto dermed av 495 artikler fra til sammen 157 ulike aviser eller ukeblader.

\section{Resultater}

Tabell 1 gir en oversikt over hva artiklene omhandlet. Den største andelen artikler var i hovedsak personhistorier, og i $35 \%$ av disse artiklene var personen en idrettsutøver. Risikofaktorer for ryggplager, behandling av ryggplager og anbefaling av forskjellige tiltak eller behandlere ble også hyppig omtalt.

Behandling, forebygging og forskning rundt ryggplager var hovedtema for $49 \%$ av ukebladartiklene, $25 \%$ av lokalavisartiklene og $17 \%$ av artiklene i riks- og regionsavisene. Lokalavisene skrev ofte om risikofaktorer og anbefalinger fra behandlere, for eksempel et nytt behandlingstilbud $\mathrm{i}$ avisens nedslagsområde. I riks- og regionsavisene skrev særlig om personer og om organisering av helsetjenester.

\section{Utredning og forebygging}

122 artikler omhandlet utredningstiltak, hyppigst utredning hos (allmenn)lege $(\mathrm{n}=85)$, røntgenundersøkelse $(\mathrm{n}=40)$ og utredning hos organspesialist $(\mathrm{n}=24) .35$ artikler

\section{Hovedbudskap}

- Norske medier skriver oftest om vond rygg i forbindelse med personhistorier, risikofaktorer og behandlingstiltak

- Medienes informasjon om utredning, behandling og forebygging av vond rygg samsvarer i betydelig grad med hovedbudskapet i norske retningslinjer for håndtering av korsryggssmerter

- Aviser og ukeblader kan bidra positivt i formidling av kunnskapsbasert helseinformasjon 


\section{Ramme 1}

\section{Kodebok brukt i kvantitativ innholdsanalyse av artikler om vond rygg i norske aviser og ukeblader}

Artikkelens hovedfokus, definert som hva artikkelen selv angir å omhandle, gjennom tittel og ingress (15 alternativer)

Hvilke utredningstiltak er nevnt (fem alternativer)? Er de anbefalt i artikkelen? Hvem er kilde (11 alternativer)? Samsvarer tiltaket med retningslinjene?

- Hvilke forebyggende tiltak er nevnt (10 alternativer)? Er de anbefalt i artikkelen? Hvem er kilde (11 alternativer)? Samsvarer tiltaket med retningslinjene?

- Hvilke behandlingstiltak er nevnt (10 alternativer)? Er de anbefalt i artikkelen? Hvem er kilde (11 alternativer)? Samsvarer tiltaket med retningslinjene?

Er noen av de sju oppfatningene om vond rygg som ble undersøkt i Aktiv rygg-kampanjen nevnt? (Man blir fortere bedre i ryggen hvis man fortsetter i jobben eller går tilbake så raskt som mulig. Ryggplager leges best av seg selv. Skiveprolaps bør opereres. Moderne bilde-/røntgenundersøkelse avdekker som regel årsaken til ryggsmerter. Alle med ryggsmerter bør undersøkes med røntgen. A ligge er beste behandling ved ryggsmerter. Ryggsmerter skal behandles med ro og hvile til de går over.]

- Er retningslinjene nevnt?
(29\%) omhandlet eller anbefalte utredningstiltak som klart var i tråd med retningslinjene. I 33 artikler (27\%) var det usikkert om omtalen var i samsvar med retningslinjene. Ingen av artiklene omhandlet eller anbefalte utredningstiltak som klart var i strid med retningslinjene.

Det var 136 artikler om forebyggingstiltak, hyppigst trening $(\mathrm{n}=58)$, generell aktivitet ( $=52)$ og diverse andre tiltak $(n=67)$, inkludert valg av riktig skolesekk $(\mathrm{n}=35) .26$ artikler om riktig skolesekk var gjengivelser av to forskjellige pressemeldinger fra det oppdragsfinansierte nyhetsbyrået Newswire, etter oppdrag fra ryggsekkprodusenten Bergans. 75 artikler $(55 \%)$ omhandlet eller anbefalte forebyggingstiltak som klart var i samsvar med retningslinjene. For 23 artiklers vedkommende $(17 \%)$ var det usikkert om omtalen var i samsvar med retningslinjene. Ingen av artiklene omhandlet eller anbefalte forebyggingstiltak som tydelig var i strid med retningslinjene.

\section{Behandling}

307 artikler omhandlet behandlingstiltak (tab 2). Kategorien «annen behandling» omfattet tiltak som hesteridning og maurbitt. 172 artikler $(56 \%)$ omhandlet eller anbefalte behandlingstiltak som tydelig var i samsvar med retningslinjene. For 95 artiklers vedkommende (31\%) var det usikkert om innholdet var i samsvar med retningslinjene, dette gjaldt særlig artikler som omhandlet kirurgi (38 artikler) og «annen behandling» (33 artikler). Som eksempel på et utsagn i en slik artikkel nevnes «Ryggsmerter kan lindres ved en operasjon eller ved behandling, men det er viktig å gjøre en innsats med egentrening og fysisk aktivitet» (Familien, 21.10. 2001). Utsagnet kan gi inntrykk av at ryggsmerter krever aktiv behandling for å gå over, men inneholder også en anbefaling som er i samsvar med retningslinjene.

Det ble ikke funnet artikler med anbefaling av behandlingstiltak som tydelig var i strid med retningslinjene. $62 \%$ av ukebladartiklene med omtale av behandlingstiltak inneholdt informasjon som var i samsvar med retningslinjene. Tilsvarende andel for artikler i lokalaviser og riks- og regionsaviser var henholdsvis $58 \%$ og $44 \%$.

\section{Oppfatninger om vond rygg}

De fleste oppfatningene om vond rygg som ble undersøkt og forsøkt påvirket i Aktiv rygg-kampanjen ble sjelden gjenfunnet $\mathrm{i}$ materialet. Oppfatninger som dreide seg om trening og aktivitet ble hyppigst gjenfunnet. I hovedsak ble feilaktige oppfatninger avkreftet og korrekte oppfatninger bekreftet i artiklene. Figur 1 viser oppfatningene som ble gjenfunnet i artiklene.

\section{Sammenlikning mellom tidsperiodene}

76 artikler var fra en periode på åtte måneder før retningslinjene ble publisert, 220 var fra året etter publiseringen og 199 fra perioden tre år senere. Korrigert for forskjellen i varighet på tidsperiodene var det $83 \%$ flere oppslag om vond rygg i perioden etter enn i perioden før utgivelsen av retningslinjene.

Det var ingen signifikante forskjeller mellom de tre tidsperiodene når det gjaldt andelen artikler som var i samsvar med retningslinjene. Det var heller ingen signifikante forskjeller mellom de tre tidsperiodene når det gjaldt forekomst av riktige versus feilaktige oppfatninger om vond rygg. Retningslinjene ble nevnt i 11 av 220 artikler i perioden etter at retningslinjene var utgitt og i to av 199 artikler i perioden tre år senere.

Tabell 1 Hva artiklene handlet om, fordelt på medietype

\begin{tabular}{|c|c|c|c|c|c|c|c|c|c|c|}
\hline & \multicolumn{2}{|c|}{$\begin{array}{l}\text { Totalt } \\
n=495\end{array}$} & \multicolumn{2}{|c|}{$\begin{array}{l}\text { Lokalaviser } \\
\qquad n=240\end{array}$} & \multicolumn{2}{|c|}{$\begin{array}{c}\emptyset \text { vrige aviser }{ }^{2} \\
\quad n=137\end{array}$} & \multicolumn{2}{|c|}{$\begin{array}{l}\text { Ukeblad } \\
n=100\end{array}$} & \multicolumn{2}{|c|}{$\begin{array}{c}\text { Tidsskrift } \\
\mathrm{n}=18\end{array}$} \\
\hline & Antall & (\%) & Antall & (\%) & Antall & (\%) & Antall & (\%) & Antall & (\%) \\
\hline Personhistorie & 108 & (22) & 38 & (16) & 46 & (34) & 24 & (24) & 0 & (0) \\
\hline Årsaker/risikofaktorer for ryggplager & 73 & (15) & 47 & (20) & 13 & (9) & 7 & (7) & 6 & (33) \\
\hline Behandling av ryggplager & 58 & (12) & 23 & (10) & 10 & (7) & 22 & (22) & 3 & (17) \\
\hline Anbefaling/reklame & 55 & (11) & 36 & (15) & 6 & (4) & 9 & (9) & 4 & (22) \\
\hline Forskning om ryggplager & 45 & (9) & 16 & (7) & 9 & (7) & 17 & (17) & 3 & (17) \\
\hline Organisering av helsetjenester & 37 & (7) & 20 & (8) & 16 & (12) & 1 & (1) & 0 & (0) \\
\hline Forebygging av ryggplager & 36 & (7) & 21 & (9) & 4 & (3) & 10 & (10) & 1 & (6) \\
\hline Arbeid/trygd/økonomi & 24 & (5) & 9 & (4) & 12 & (9) & 2 & (2) & 1 & (6) \\
\hline Skade/ulykke & 24 & (5) & 10 & (4) & 14 & (10) & 0 & (0) & 0 & (0) \\
\hline Annet & 11 & (2) & 4 & (2) & 4 & (3) & 3 & (3) & 0 & (0) \\
\hline Alternativ medisin & 9 & (2) & 5 & (2) & 0 & (0) & 4 & (4) & 0 & (0) \\
\hline Idrett & 7 & (1) & 5 & (2) & 1 & (1) & 1 & (1) & 0 & (0) \\
\hline Kirurgi & 6 & (1) & 4 & (2) & 2 & (1) & 0 & (0) & 0 & (0) \\
\hline Bivirkning/uheldig hendelse & 2 & (0) & 2 & (1) & 0 & (0) & 0 & (0) & 0 & (0) \\
\hline
\end{tabular}

1 Prosentandel i forhold til den enkelte medietype

${ }^{2}$ Består av regionsaviser $(n=54)$, riksaviser $(n=63)$, meningsaviser $(n=12)$ og nyhetsbyråer $(n=8)$ 


\section{Diskusjon}

Denne studien viser at artikler om ryggsmerter i norske aviser og ukeblader særlig er basert på enkeltpersoners erfaringer. Dette funnet er i samsvar med et generelt inntrykk av at medieoppslag gjerne knyttes til enkeltmenneskers opplevelser og til fortellinger som mange kan identifisere seg med. Ofte dreier dette seg om profilerte og godt kjente personer, gjerne utøvere i populære sportsgrener.

Risiko- og årsaksfaktorer, behandling og anbefaling av tiltak var andre vanlige temaer i artiklene. En av nyhetssakene som ble gjengitt i spesielt mange aviser, dreide seg om viktigheten av at skolebarn bærer en god og ikke for tung sekk for å unngå ryggplager. En slik påstand er det ikke funnet god dokumentasjon for. Å bære stroppen på ene skulderen var i en studie det eneste som i svak grad korrelerte med ryggplager (16). Disse artiklene var basert på to pressemeldinger fra et nyhetsbyrå på oppdrag fra en ryggsekkprodusent. Bruken av artikler fra oppdragsfinansierte nyhetsbyråer er omdiskutert (17) og kan bryte med tekstreklameplakaten (18). I vår sammenheng demonstrerer funnet at kommersielle aktører har interesser i hvordan ryggplager blir omtalt og befester inntrykket av at helsejournalistikk kan fungere som fordekt reklame (4).

I rundt en firedel av artiklene ble det nevnt ulike utredningstiltak, hyppigst allmennmedisinsk og bildediagnostisk utredning. Dette bekrefter at fastlegen oppfattes som den vanligste primærkontakt for ryggpasienter, men kan også tyde på at bildediagnostikk er den supplerende utredningsmodalitet som befolkningen har størst tiltro til $(13,14)$. Selv om noen av artiklene inneholdt tvetydig eller usikker informasjon, var det ingen som tydelig var i strid med retningslinjene, verken når det gjaldt utredning, behandling eller forebygging. Rundt halvparten av artiklene om forebygging understøttet hovedbudskapet om trening og generell aktivitet, slik det også fremkommer av pasientbrosjyren basert på retningslinjene (15).

Godt over halvparten av artiklene omhandlet behandlingstiltak, og i et flertall av disse var innholdet $i$ samsvar med anbefalingene i de norske retningslinjene om trening, øvelser og generell aktivitet. For mange artikler var det usikkert om innholdet var i samsvar med retningslinjene, men i de fleste av disse var årsaken til dette at det ikke var gitt noen tydelig informasjon som kunne vurderes i forhold til dem.

Det er godt dokumentert at et flertall av befolkningen har brukt eller kan tenke seg å anvende såkalt alternativ (komplementær) behandling, ikke minst ved uspesifikke og komplekse lidelser der behandlingstilbudet fra skolemedisinen ofte er mangelfullt og/eller kan gi bivirkninger (2). Vi var derfor overrasket over at så få artikler omhandlet alternativ behandling, feilbehandling og bivirkninger av legeforordnet behandling.

Aktiv rygg-unders $ø$ kelsen viste at ryggre-

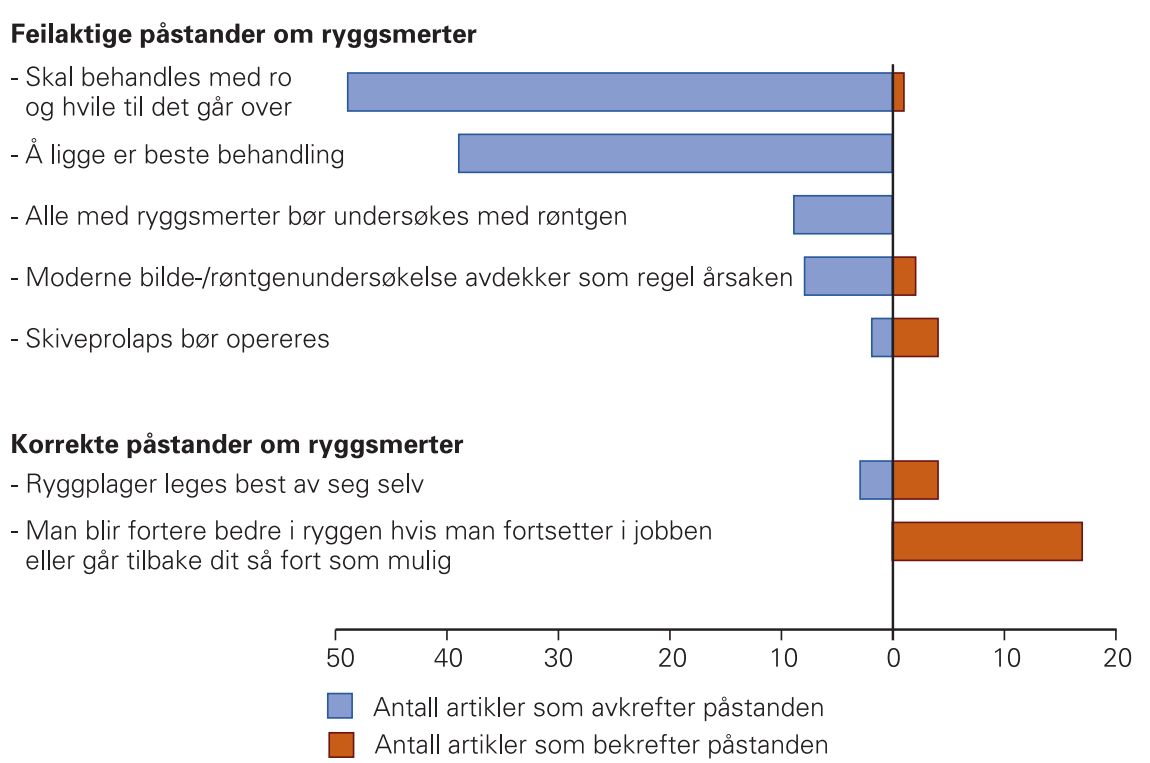

Figur 1 Feilaktige og korrekte påstander om ryggsmerter i norske medier i de undersøkte periodene

laterte oppfatninger $\mathrm{i}$ befolkningen er ferd med å endres i retning av hovedbudskapet $\mathrm{i}$ de omtalte retningslinjene $(13,14)$. Våre funn peker i samme retning - ved at feilaktige oppfatninger stort sett ble avkreftet og korrekte oppfatninger ble bekreftet.

Antall artikler i årene etter publisering av retningslinjene var klart høyere enn i perioden før. Ifølge overvåkningsbyrået var søkeprosedyrene uendret gjennom alle periodene. Pressemeldingen om riktig skolesekk førte til mange artikler sommeren 2002, og dette forklarer en stor del av økningen. Artiklene som omhandlet retningslinjene, står for noe av økningen. Likevel gjenstår det en betydelig og overraskende økning som vi ikke kan forklare med våre metoder. Én mulig forklaring er at det kan ha vært en økt oppmerksomhet i samfunnet om vond rygg etter publiseringen av retningslinjene.
Innholdet i artiklene fra tiden før publiseringen var like mye i samsvar med retningslinjene som innholdet $\mathrm{i}$ artiklene som kom ut etter publiseringen. Vi har dermed ingen holdepunkter for å si at retningslinjene i seg selv har påvirket hva norske medier skriver om vond rygg. Vi kan anta at den behandlingsmessige endringen når det gjelder vond rygg - fra ro og sengeleie til aktivitet - allerede var kjent blant journalistene og deres kilder. Denne studien gir ingen kunnskap om hvordan helsetjenesten kan samarbeide med mediene for å få frem viktige budskap, men den viser at mediene og helsetjenesten kan dra i samme retning når det gjelder å spre kunnskapsbasert helseinformasjon i befolkningen.

En kvantitativ innholdsanalyse vil ikke fange opp alle aspekter ved de studerte tekstene (19). Valget av metode ble gjort for få en bred, systematisk og representativ kart-

Tabell 2 Omtale av forskjellige tiltak for behandling av ryggsmerter ${ }^{1}(\mathrm{~N}=307)$

\begin{tabular}{|c|c|c|c|c|c|c|c|c|}
\hline & \multicolumn{2}{|c|}{ Totalt } & \multicolumn{2}{|c|}{$\begin{array}{l}\text { Tiltaket anbe- } \\
\text { fales og/eller } \\
\text { angis å ha } \\
\text { positiv effekt }\end{array}$} & \multicolumn{2}{|c|}{$\begin{array}{c}\text { Tiltaket nevnes } \\
\text { uten anbefaling } \\
\text { ellerkonklusjon } \\
\text { om effekt }\end{array}$} & \multicolumn{2}{|c|}{$\begin{array}{l}\text { Tiltaket fra- } \\
\text { rådes og/eller } \\
\text { angis ikke å } \\
\text { ha effekt }\end{array}$} \\
\hline & Antall & $(\%)$ & Antall & $(\%)$ & Antall & $(\%)$ & Antall & $(\%)$ \\
\hline Trening & 112 & $(100)$ & 97 & (87) & 14 & (13) & 1 & (1) \\
\hline Generell aktivitet & 89 & $(100)$ & 85 & (96) & 4 & (4) & 0 & (0) \\
\hline Kirurgi & 77 & $(100)$ & 27 & (35) & 44 & (57) & 6 & (8) \\
\hline Annen behandling & 75 & $(100)$ & 64 & (85) & 8 & (11) & 3 & (4) \\
\hline Fysioterapi & 68 & (100) & 26 & (38) & 30 & (44) & 12 & (18) \\
\hline Kiropraktikk & 63 & (100) & 24 & (38) & 32 & (51) & 7 & (11) \\
\hline Legemidler & 47 & $(100)$ & 23 & (49) & 18 & (38) & 6 & (13) \\
\hline Ro & 45 & $(100)$ & 17 & (38) & 4 & (9) & 24 & (53) \\
\hline Alternativ terapi & 31 & (100) & 20 & (65) & 4 & (13) & 7 & (23) \\
\hline
\end{tabular}


legging over tid av avisers og ukebladers omtale av ryggplager. Kodingen av artiklene var nødvendigvis basert på skjønn. Denne potensielle feilkilden ble forsøkt redusert gjennom gjentatte pilotkodinger og diskusjon mellom koderne. Overvåkingsbyrået undersøkte en del av avisene og ukebladene manuelt, og noen artikler om ryggplager kan ha blitt oversett i denne prosessen. Metoden ble likevel valgt fordi det ikke finnes digitale søkeverktøy som dekker alt av trykt presse.

\section{Konklusjon}

Norske aviser og ukebladet omtaler i hovedsak personhistorier, risikofaktorer og behandling $\mathrm{i}$ artikler om vond rygg. Informasjonen om forebygging, utredning og behandling av ryggsmerter samsvarer i betydelig grad med norske tverrfaglige retningslinjer.

Oppgitte interessekonflikter: Ingen

\section{Litteratur}

1. Mæland JG. Forebyggende helsearbeid - i teori og praksis. Oslo: Tano/Aschehoug, 1999
2. Lærum E. Frisk, syk eller bare plaget? Innføring medisinsk nøkkelkunnskap. Bergen: Fagbokforlaget, 2005.

3. Romøren TI. Helsevesenet på Dagsrevyen. Tidsskr Nor Lægeforen 2004: 124: 3212-6.

4. Høye S, Hjortdahl P. «Ny vidunderpille»- hva skriver norske aviser om nye legemidler. Tidsskr Nor Lægeforen 2002; 122: 1671-6.

5. Hafstad A. På helsa løs? Når pressen tar pulsen på Helse-Norge. Kristiansand: IJ Forlaget, 2006.

6. Andreassen HV. Helserelatert bruk av Internett i den norske befolkningen. Tidsskr Nor Lægeforen 2006; 126: 2950-2.

7. Nylenna M. Journalister er fra Jupiter, medisinere er fra Mars. Tidsskr Nor Lægeforen 2000; 120 2828

8. Swensen E. red. Diagnose: risiko. Oslo: Universitetsforlaget, 2000: 114-23.

9. Ihlebæk C, Lærum E. Plager flest - koster mest: Muskel-skjelettlidelser i Norge. Rapport nr 1. Oslo: Nasjonalt Ryggnettverk, 2004

10. Brage S, Lærum E. Rygglidelser i Norge - en epidemiologisk beskrivelse. Tidsskr Nor Lægeforen 1999: 119: 1619-23.

11. Waddel G. The Back Pain Revolution. United Kingdom: Churchill Livingstone, 1999

12. Lærum E, Brox JI, Storheim K et al. Nasjonale kliniske retningslinjer. Korsryggsmerter: med og uten nerverotaffeksjon. Oslo: FORMI/Sosial- og helsedirektoratet, 2007

13. Werner EL. Media campaign for improving knowledge, attitude and practice in low back pain - an evaluation of the «Active Back» project. Doktoravhandling. Bergen: Universitetet i Bergen, 2008.

14. Ihlebaek C, Eriksen HR. Are the «myths» of low back pain alive in the general Norwegian population? Scand J Public Health 2003; 31: 395-8.

15. Lærum E, Dullerud R, Kirkesola G et al. Akutte korsryggsmerter - tverrfaglige kliniske retningslinjer. Oslo: Nasjonalt ryggnettverk, Formidlingsenheten, 2002.

16. Skoffer B. Low back pain in 15- to 16-year-old children in relation to school furniture and carrying of the school bag. Spine (Phila Pa 1976) 2007; 32: E713-7.

17. Allern S. Når kildene byr opp til dans: søkelys på PR-byråene og journalistikken. Oslo: Pax, 1997.

18. Pressens Faglige utvalg. Tekstreklameplakaten. http://presse.no/Pressens_Faglige_Utvalg_PFU/ Tekstreklameplakaten (18.10.2010).

19. Østbye H, Helland K, Knapskog K et al. Metodebok for medievitenskap. Bergen: Fagbokforlaget, 2007: 230

Mottatt 12.3. 2010, første revisjon innsendt 1.7. 2010, godkjent 4.11. 2010.

Medisinsk redaktør Petter Gjersvik. 